\title{
Physical Properties and Stress Analysis of Low Dielectric Polyimide Films Containing Adamantane Pendant Group
}

\author{
Dong Keun Yoo, Sang Kyun Lim, ${ }^{*}$ Tae Ho Yoon, ${ }^{*}$ and Dukjoon $\mathrm{KIM}^{\dagger}$ \\ Department of Chemical Engineering, Sungkyunkwan University, Suwon, Kyungki 440-746, Korea \\ ${ }^{*}$ Department of Materials Science, Kwangju Institute of Science and Technology, Kwangju 500-712, Korea
}

(Received April 7, 2003; Accepted June 27, 2003)

\begin{abstract}
Low dielectric polyimides were synthesized from a new diamine, bis(4-aminophenyl)-1-adamantyl phosphine oxide (DAAPO) containing adamantane cage structured group in the pendant position. Thermomechanical properties were investigated using differential scanning calorimetry (DSC), thermogravimetric analysis (TGA), and thermomechanical analyzer (TMA). The thickness dependence of dielectric constant was measured using a LCR meter, and the results were compared with those of other polyimide systems reported. Variation of stress during film coating and annealing processes was analyzed using a bending beam curvature measurement system complemented with an in-situ film thickness measurement system, the interferometer. Stress was developed as solvent evaporated during film baking process, and the residual stress was obtained when the coated films were prepared. The stress behavior was significantly affected by ramping and annealing schedules.
\end{abstract}

KEY WORDS Polyimide / Dielectric Constant / Adamantane / Cage Structure / Stress /

Aromatic polyimides have been used as dielectric, coating, and adhesive layers in microelectronics fabrications, because they have excellent electrical, chemical, thermal, and mechanical properties compared to other organic polymers. ${ }^{1-5}$

In order to fabricate a high performance chip, however, solutions to some problems should be addressed. One is about the dielectric performance. As dielectric constants of commercial polyimides (PIs) are reported to be higher than 3 , it should be lowered to transport more signals through more integrated circuits. The residual stress is another problem, especially in the thin polymer film application for chip and wire packaging. Stress is usually developed by thermal expansion difference between the film and substrate. Organic/inorganic pairs like PI/silicon wafer imposed high stress due to relatively high thermal expansion difference. When it is considerable in multiplayer fabrication process, it sometimes results in cracking, delamination, or bending of films.

Among many trials to reduce the dielectric constant and residual stress, one has recently proposed introduction of nano or molecular foams in PI matrix. This was based on the idea that the dielectric constant of air is close to 1 and that the stress is significantly affected by relative density of polymer foams, $\rho / \rho_{0}$; moduli of foams are known to be proportional to $\left(\rho / \rho_{0}\right),{ }^{2,6}$ under the circumstances that thermal expansion coefficients of bulk and foam polymers are almost the same. More than 10 year trials for insertion of nano or molecular foams in PIs are summarized by two approaches: i) the phase separation by heat and non-solvent during preparation of PI systems, ${ }^{7}$ and ii) the synthesis of block copolymer composed of polyimide and thermally degradable polymer. ${ }^{8}$ Thermal degradation of the second component leaves nano-scaled pores behind it. Not many of these, however, were successfully industrialized, because their preparation process was too complicated and the resulting material properties were not fairly satisfied.

Preparation of polyimide containing cage structured molecules is another strategy to reduce dielectric constant and residual stress in their application as microelectronic multilayers. ${ }^{9-13}$ Among some cage structured molecules, adamantane (tricyclo[3,3,1,1] decane) is characterized by fused chair-form cyclohexane ring structure. ${ }^{14,15}$ As this substance has high thermal and oxidation resistance, it has ever been inserted into the backbone of a few polymeris systems, e.g., polyimides, polysulfones, polyesters, and polyamides ${ }^{16-23}$ to increase the thermal and oxidative stability.

As this cage molecule is expected to induce dilution effect on the polar imide groups due to its fully aliphatic hydrocarbon structure, ${ }^{22,23}$ recently, new polyimides containing adamantane in the pendant position were synthesized in our group. As the synthesis and chemical identification of these types of PIs were reported in detail in other contribution, ${ }^{24}$ in this study, dielectric constant and stress behavior were concentrated, especially when these polyimides were applied as coated films. Fundamental thermo-mechanical properties were also investigated.

${ }^{\dagger}$ To whom correspondence should be addressed (Tel: +82-31-290-7250, Fax: +82-31-290-7272, E-mail: djkim@skku.edu). 


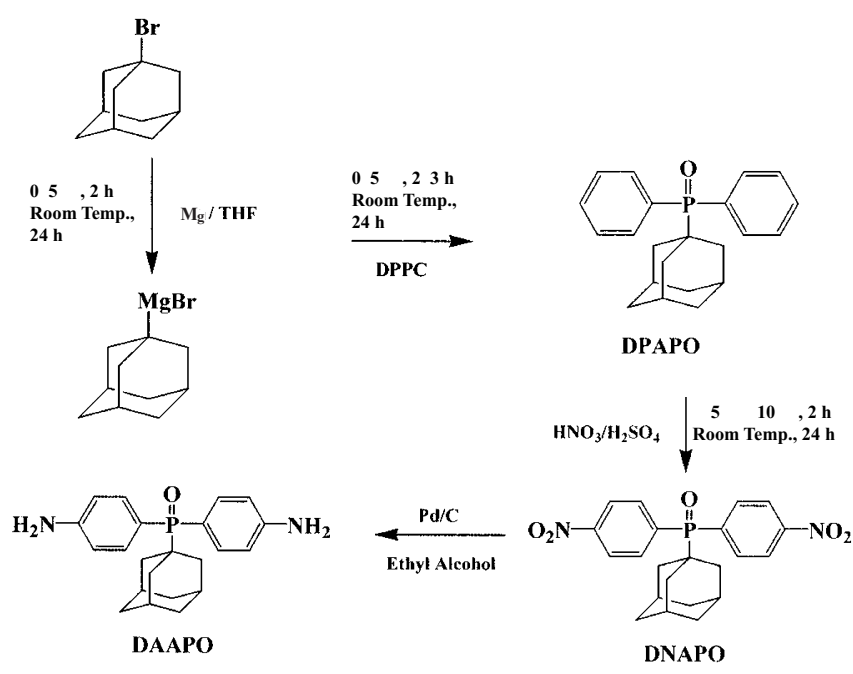

Figure 1. Synthetic scheme of bis(4-aminophenyl)-1adamantyl phosphine oxide (DAAPO).

\section{EXPERIMENTAL}

\section{Synthesis of Cage Monomers}

Bis(4-aminophenyl)-1-adamantyl phosphine oxide (DAAPO), a type of diamines possessing adamantane group in pendant position was synthesized. Synthetic scheme of DAAPO is illustrated in Figure 1. First, 1-adamantyl diphenyl phosphine oxide (DPAPO) was synthesized through Grignard reaction of 1-bromoadamantane (Aldrich, Milwaukee, WI) and diphenyl phosphine chloride (Aldrich). Second, DPAPO, the product of first step was nitrated using sulfuric acid and nitric acid to synthesize bis(4nitrophenyl)-adamantyl phosphine oxide (DNAPO). The next step involved synthesis of DAAPO. DAAPO was produced by hydrogenation of DNAPO in the presence of $\mathrm{PD} / \mathrm{C}$ catalyst. Detailed procedure and condition of each synthetic and purification step are represented in other report. ${ }^{24}$ The chemical structure and purity were identified ${ }^{24}$ using infrared spectroscopy (FTIR, IR 2000, PerkinElmer) and ${ }^{1} \mathrm{H}$ and ${ }^{31} \mathrm{P}$ fourier transform nuclear magnetic resonance spectroscopy (FTNMR, 300 MHz, JEOL), etc.

\section{Synthesis of Polyimide Containing Adamantane Pen- dant Group}

Polyimides containing pendant adamantane was synthesized from the reaction of DAAPO with 2,2bis(3,4-dicarboxyphenyl) hexafluoropropane dianhydride (6FDA, from Chriskev). Poly(amic acid) (PAA) was first prepared. DAAPO, $5 \mathrm{~g}(13.63 \mathrm{mmol})$, was dissolved in $50 \mathrm{~mL}$ of dry $N$-methylpyrrolidone (NMP) in a $500 \mathrm{~mL}$ three neck flask equipped with a mechanical stirrer, a thermometer, a condenser, and a $\mathrm{N}_{2}$ inlet line. After phthalic anhydride (PA), an end

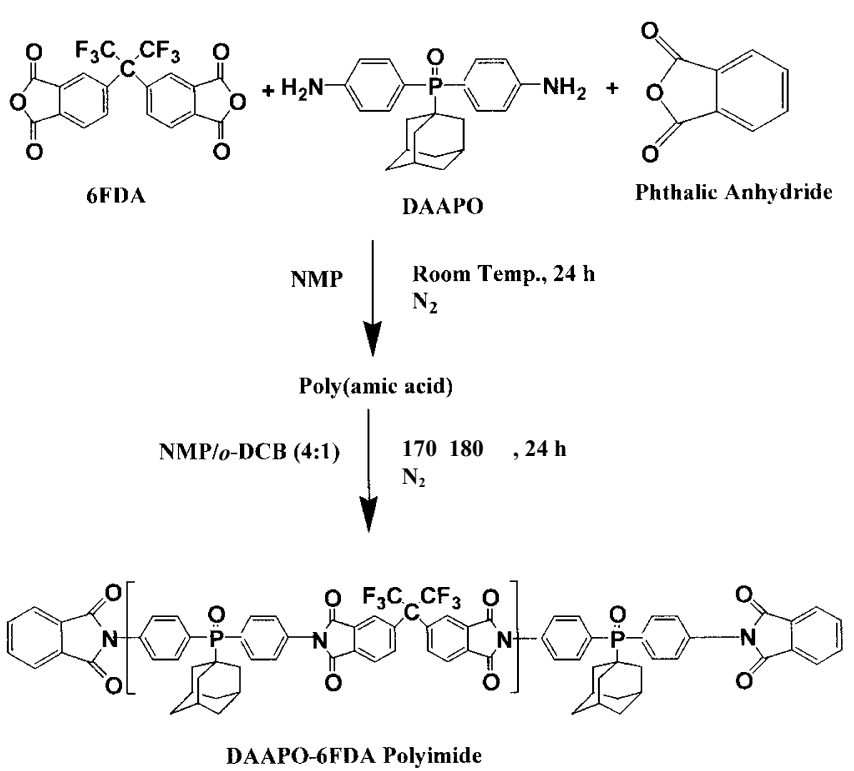

Figure 2. Synthetic scheme of DAAPO-6FDA polyimide via the two step route.

capping agent, $0.16 \mathrm{~g}(1.1 \mathrm{mmol})$, was introduced to the DAAPO/NMP solution to attach non reactive end groups, 6FDA, $5.82 \mathrm{~g}(13.09 \mathrm{mmol})$, was slowly added to the reactant solution. After reaction for $24 \mathrm{~h}$ under nitrogen atmosphere, the yellow colored product, PAA, was obtained.

Full imidization reaction was conducted in solution state. PAA was dissolved in NMP/o-DCB (80/20 vol\%) co-solvent. The PAA solution was mechanically stirred in a flask at $175^{\circ} \mathrm{C}$ for $24 \mathrm{~h}$ under nitrogen atmosphere. After the mixture was cooled down to room temperature, the product, PI, was precipitated in methanol. Once filtered and dried, PI products were dissolved in chloroform (20-30 wt\%) to remove residual impurities. White PI samples were filtered and dried in a vacuum oven at $200^{\circ} \mathrm{C}$ for $12 \mathrm{~h}$ before storage.

The synthetic scheme of PI is illustrated in Figure 2. Molecular weights of PIs synthesized were measured using a gel permeation chromatography (GPC, Waters M38003, M515). The chemical structure of PI products was identified using FT-IR spectroscopy (IR 2000, PerkinElmer) and ${ }^{1} \mathrm{H}$ and ${ }^{31} \mathrm{P}$ FT-NMR spectroscopy $(300 \mathrm{MHz}, \mathrm{JEOL}) .{ }^{24}$

\section{Measurement of Physical Properties}

Glass transition temperature was measured using a differential scanning calorimetry (DSC, TA-2910, PerkinElmer). $10 \mathrm{mg}$ of PI sample was heated from 25 to $400{ }^{\circ} \mathrm{C}$ at the scanning rate of $10^{\circ} \mathrm{C} \mathrm{min}^{-1}$ in the nitrogen atmosphere. The second heating thermograms were obtained after the first heated polymer melts were quenched to room temperature. Thermal stability was examined using a thermogravimetric an- 
$\delta$ is proportional to $\triangle$

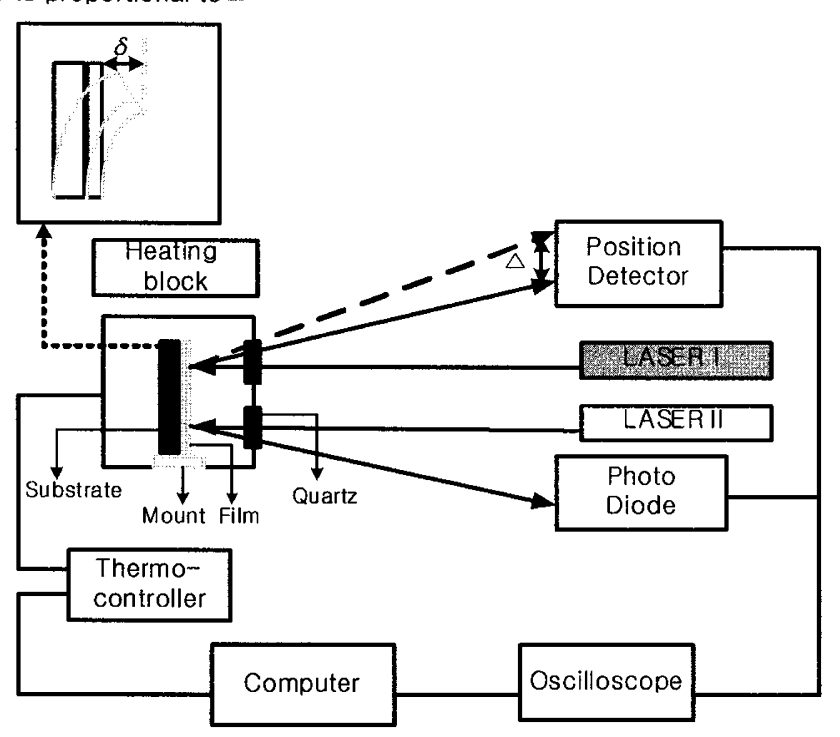

Figure 3. Schematic of the in-situ measurement system for film thickness and bending curvature.

alyzer (TGA, TA 2910, PerkinElmer). Measurements were conducted from room temperature to $660^{\circ} \mathrm{C}$ at the scanning rate of $10^{\circ} \mathrm{C} \mathrm{min}^{-1}$ in the air and nitrogen atmosphere. Samples were dried to remove residual solvent before measurement. Thermomechanical analyzer (TMA, SS6100, PerkinElmer) was used to measure the linear thermal expansion coefficients of PI films. Measurements were conducted from room temperature to $300^{\circ} \mathrm{C}$ at the scanning rate of $20^{\circ} \mathrm{C} \mathrm{min}^{-1}$ in the nitrogen environment. Intrinsic viscosity was measured using a Cannon-Ubbelohde viscometer in $\mathrm{N}$ methylpyrrolidone (NMP) at $25^{\circ} \mathrm{C}$. Dielectric constant was measured using a LCR meter (HP4294, Hewlett Packard) at $1 \mathrm{MHz}$ frequency. For this measurement, PI films were spin-coated on the $<100>$ type silicon wafers in the thickness of $360 \mu \mathrm{m}$ (Hyundai Electronics Company). Aluminum electrodes were vacuum deposited on both film surfaces. The film thickness was controlled by solution concentration and revolution speed. It was ranging from 130 to $1140 \mathrm{~nm}$, and was measured using an alpha step (500, KLA-Tencor, USA) and then confirmed using a scanning electron microscope (SEM, XL-30 Philips, Netherlands).

\section{Measurement of Stress and Film Thickness}

PIs were dissolved in tetrachloroethane (TCE). The polymer solution was coated using a spin coater (model 1-EC101DT-R485, Headway, USA) at $1800 \mathrm{rpm}$ for $30 \mathrm{~s}$ on the $<100>$ type $360 \mu \mathrm{m}$ silicon wafer (Hyundai Electronics Company). The film-coated substrates were baked by raising temperature in the nitrogen environment to remove solvent absorbed in films. The ramping rate was 2,4 , or $6^{\circ} \mathrm{C} \mathrm{min}^{-1}$, respectively.
The stress change during the fabrication of polyimide films was analyzed using a bending beam curvature measurement system as shown in Figure 3. The bending curvature measurement system was composed of an $8 \mathrm{~mW}$ He-Ne laser I (model 1134P, Uniphase), a position sensitive detector (model 1239, UDT sensors), and an oscilloscope (model OS3040, LG Precision, Korea). The beam from laser I was focused on one end spot of the film. As the beam reflected from the film was initially positioned at the center of the sensor, it moved along the $\mathrm{x}$ - or $\mathrm{y}$-axis of the sensor as the film was being bent. Displacement of beam position from the initial spot induced linear change of output (voltage) from the position-detecting sensor. The output signal was magnified by an amplifier (model 301DIV, UDT sensors), before it was sent to a personal computer. The end deflection, $\delta$, was determined from the beam position displacement, $\Delta$, using the calibrated relationship between them.

Film thickness was in-situ measured with bending curvature. The film thickness change during drying of polymer film was measured using a laser interferometer system as shown in Figure 3. Polyimide samples in the dimension of $71 \times 9 \times 0.003( \pm 10 \%)$ (in $\mathrm{mm}$ ) were clamped vertically in a heating box purged with nitrogen gas. A temperature controller (model 3000, LFE Instruments) was used to stabilize the temperature inside the heating box. The beam with the wavelength of $632.8 \mathrm{~nm}$ from $1 \mathrm{~mW} \mathrm{He}-\mathrm{Ne}$ laser (model 1507-0, Uniphase, USA) was focused on a fixed spot of polymer film. The laser beam reflected from the film was interfered due to the optical path length difference between the beam reflected from the surface and that from the bottom of the film. A silicone photodiode (model S2386-8 K, Hamamatsu, USA) was used to detect the interfered beam intensity, and a personal computer was used to store the data after digitalization by an A/D converting multimeter (model Fluke45, Fluke, Germany). All measurements were performed in a black box to minimize the surrounding light, and all instruments were placed on the optical table (Edmund Scientific Co., USA) to reduce environmental noise.

\section{RESULT AND DISCUSSION}

\section{Physical Properties of Cage Molecular PIs}

Molecular weight, thermo-mechanical properties of polyimides derived from DAAPO and 6FDA are summarized in Table I. The number average molecular weight and intrinsic viscosity of polyimides prepared were about $19600 \mathrm{ggmol}^{-1}$ and $0.24 \mathrm{dL} \mathrm{g}^{-1}$, respectively, and these values were enough to prepare tough polymer films by casting from TCE solution. The glass 
Table I. Physical properties of DAAPO-6FDA polyimide

\begin{tabular}{|c|c|c|c|c|c|c|}
\hline & \multirow{2}{*}{$\begin{array}{c}T_{\mathrm{g}} \\
\left({ }^{\circ} \mathrm{C}\right)\end{array}$} & \multicolumn{2}{|c|}{$T_{\mathrm{d}}\left({ }^{\circ} \mathrm{C}\right)$} & \multirow{2}{*}{$\begin{array}{c}\eta \\
\left(\mathrm{dL} \mathrm{g}^{-1}\right)\end{array}$} & \multirow{2}{*}{$<M_{\mathrm{n}}>$} & \multirow{2}{*}{$\alpha_{Z}\left({ }^{\circ} \mathrm{C}^{-1}\right)$} \\
\hline & & Air & $\mathrm{N}_{2}$ & & & \\
\hline DAAPO-6FDA PI & 353 & 508 & 517 & 0.24 & 19600 & $6.927 \times 10^{-5}$ \\
\hline
\end{tabular}

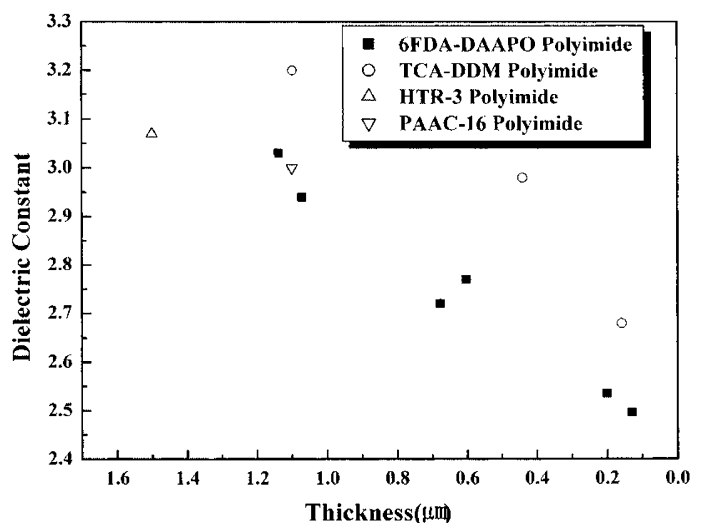

Figure 4. Thickness dependence of dielectric constant for various polyimide films; (ロ) 6FDA-DAAPO, ( $\bigcirc)$ poly(diphenylmethane-2,3,5-tricarboxycyclopentyl acetic imide $\left(\right.$ TCA-DDM) ${ }^{26}(\triangle)$ Selectilux ${ }^{\circledR}$ HTR-3 (EM industry) and $(\nabla)$ PAAC-16 (PMDA-ODA), ${ }^{27}$ respectively.

transition temperature was as high as those of other aromatic polyimide, as the bulky and rigid adamantly element increased the rigidity of polymer chain. Adamantane containing polyimide exhibited excellent thermal stability, as it was stable up to $500^{\circ} \mathrm{C}$. No degradation was observed below $500^{\circ} \mathrm{C}$ and only $5 \mathrm{wt} \%$ loss was took place $508^{\circ} \mathrm{C}$ in air and $518^{\circ} \mathrm{C}$ in nitrogen atmosphere. The linear expansion coefficient, $6.9 \times 10^{-5}{ }^{\circ} \mathrm{C}^{-1}$, was also almost the same as those of commercial PI ones. ${ }^{25}$

\section{Stress Analysis of Cage Molecular PI Films}

Figure 4 shows the film thickness dependence of dielectric constant of polyimide films containing adamantane pendant group. As the film thickness decreased from $1.14 \mu \mathrm{m}$ to $130 \mathrm{~nm}$, the dielectric constant reduced form 3.03 to 2.49 ( $\pm 5 \%$ uncertainty). It is because molecules were aligned in more ordered state, when coated in thinner films. The dielectric constants of present PI samples were lower than those of other bulk PIs reported. ${ }^{26,27}$

Founded on the bending beam theory, ${ }^{28}$ the equibiaxial stress $\sigma_{\mathrm{f}}$, is given by eq 1 , when the thickness and Young's modulus of substrate, $d_{\mathrm{s}}$ and $E_{\mathrm{s}}$, are much larger than those of film, $d_{\mathrm{f}}$, and $E_{\mathrm{f}}$, respectively,

$$
\sigma_{\mathrm{f}}=\frac{1}{6 R} \times \frac{E_{\mathrm{s}} d_{\mathrm{s}}^{2}}{\left(1-\gamma_{\mathrm{s}}\right) d_{\mathrm{f}}}
$$

Here, $\gamma_{\mathrm{s}}$ and $R$ are the Poisson's ratio and bending curvature of the substrate, respectively.

In this study, the stress was determined from the in- situ measurement of $R$ and $d_{\mathrm{f}}$ since the substrate properties such as $E_{\mathrm{s}}, d_{\mathrm{s}}$, and $\gamma_{\mathrm{s}}$ are invariant during film preparation process. As the bending curvature, $R$ in eq 1 has correlation with the end deflection of film-coated substrate, $\delta$ as in eq 2, and $\delta$ is also correlated with $\Delta$ by simple geometric analysis, $R$ can be determined by measuring $\Delta$.

$$
R=\frac{2 \delta}{l^{2}}
$$

where $l$ indicates the length of film/substrate composite strip.

The film thickness change, $\Delta d_{\mathrm{f}}$, during the drying process was determined using eq 3 where $\lambda_{\text {beam }}$ is the wavelength of laser beam, $n_{\mathrm{s}}$ is the refractive index of solvent, and $\phi$ the phase difference between the lights reflected from film surface and from film/substrate interface. Eq 3 could be applied when the volume of film was assumed to be sum of volumes of polymer and solvent, and the refractive index of film to be the volume fractional average of two components. Total film thickness change during drying was determined by counting the number of fringes, as each interval between the consecutive fringe corresponds to the reduction of film thickness given by eq $3 .^{29}$

$$
\frac{\Delta d_{\mathrm{f}}}{\text { fringe }}=\left(\frac{\mathrm{d} \phi / d d_{\mathrm{f}}}{2 \pi}\right)^{-1}=\frac{\lambda_{\text {beam }}}{2 n_{\mathrm{s}}}
$$

Figures $5 \mathrm{a}$ and $5 \mathrm{~b}$ show the in-situ measured voltage signal and sinusoidal interference intensity, respectively when PI films were dried from room temperature to $300^{\circ} \mathrm{C}$ at the scanning rate of $2{ }^{\circ} \mathrm{C} \mathrm{min}^{-1}$. In Figure 3 , the voltage signal is linearly correlated with the displacement of reflected beam spot on the position detector. In Figure 5b, the film thickness change associated with two consecutive fringes is approximately $0.212 \mu \mathrm{m}$, because the laser wavelength $\lambda$ and the solvent (TCE) refractive index, $n, 0.6328 \mu \mathrm{m}$ and $1.494,{ }^{30}$ respectively. As 4 fringes were detected for complete drying, total film thickness decreased was $0.848 \mu \mathrm{m}$. This film thickness reduction resulted from evaporation of solvent.

The stress and film thickness change during film preparation process could be obtained from the raw data in Figures 5a and 5b and eqs 1 and 3. In calculation of stress, the initial thickness of film and substrate, $d_{\mathrm{f}}$ and $d_{\mathrm{s}}$ were 3 and $360 \mu \mathrm{m}$, and Young's modulus of substrate, $E_{\mathrm{s}} 100 \mathrm{GPa}$, respectively. In Figures 6 and 7, 

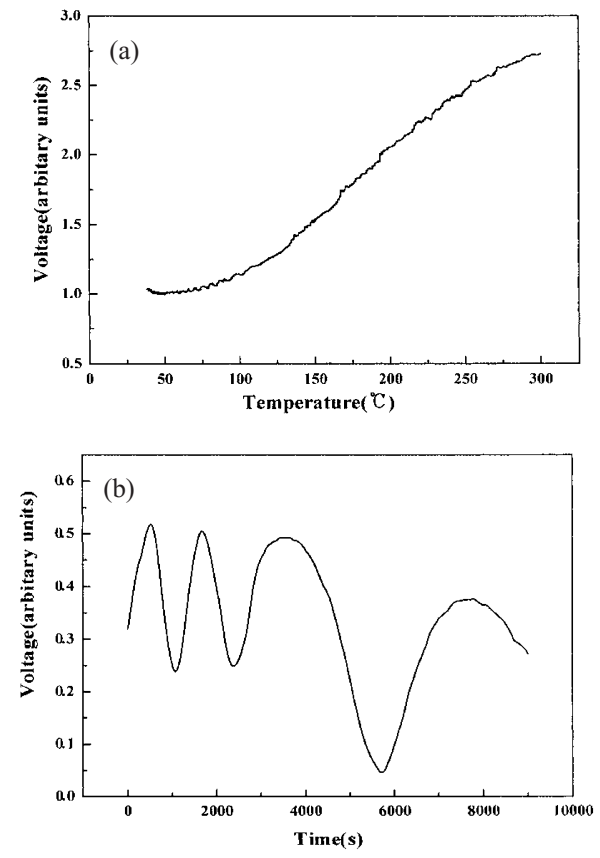

Figure 5. (a) Bending beam displacement and (b) sinusoidal interference voltage traces during PI film preparation process at the scanning rate of $2^{\circ} \mathrm{C} \mathrm{min}^{-1}$.

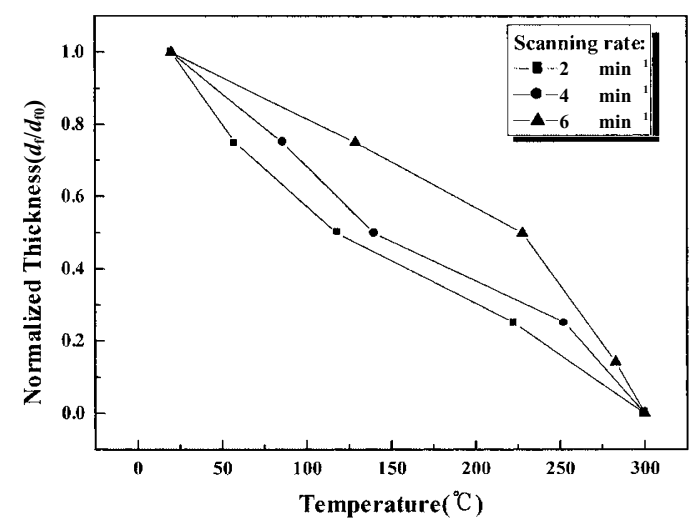

Figure 6. Normalized film thickness change during the PI film preparation process at the temperature scanning rates of 2,4 , and $6^{\circ} \mathrm{C} \mathrm{min}^{-1}$, respectively. Subscript 0 denotes the initial state.

the resulting film thickness and stress changes are represented at the scanning rates of 2,4 , and $6^{\circ} \mathrm{C} \mathrm{min}^{-1}$, respectively. Both film thickness and stress curves were shifted to right (higher temperatures), as the temperature scanning rates increased in the heating schedule. It means that the solvent evaporation occurred at higher temperatures at higher scanning rates. The scanning rate effect on the film thickness and stress was very similar each other in their shifted temperature range. The film/wafer strips gained the residual stress of 30 $60 \mathrm{MPa}$ at room temperature.

Figure 8 shows the temperature dependence of stress for $\mathrm{PI} /$ wafer strips after films have been completely dried. Before measurement, samples had been annealed above the glass transition temperature to reduce
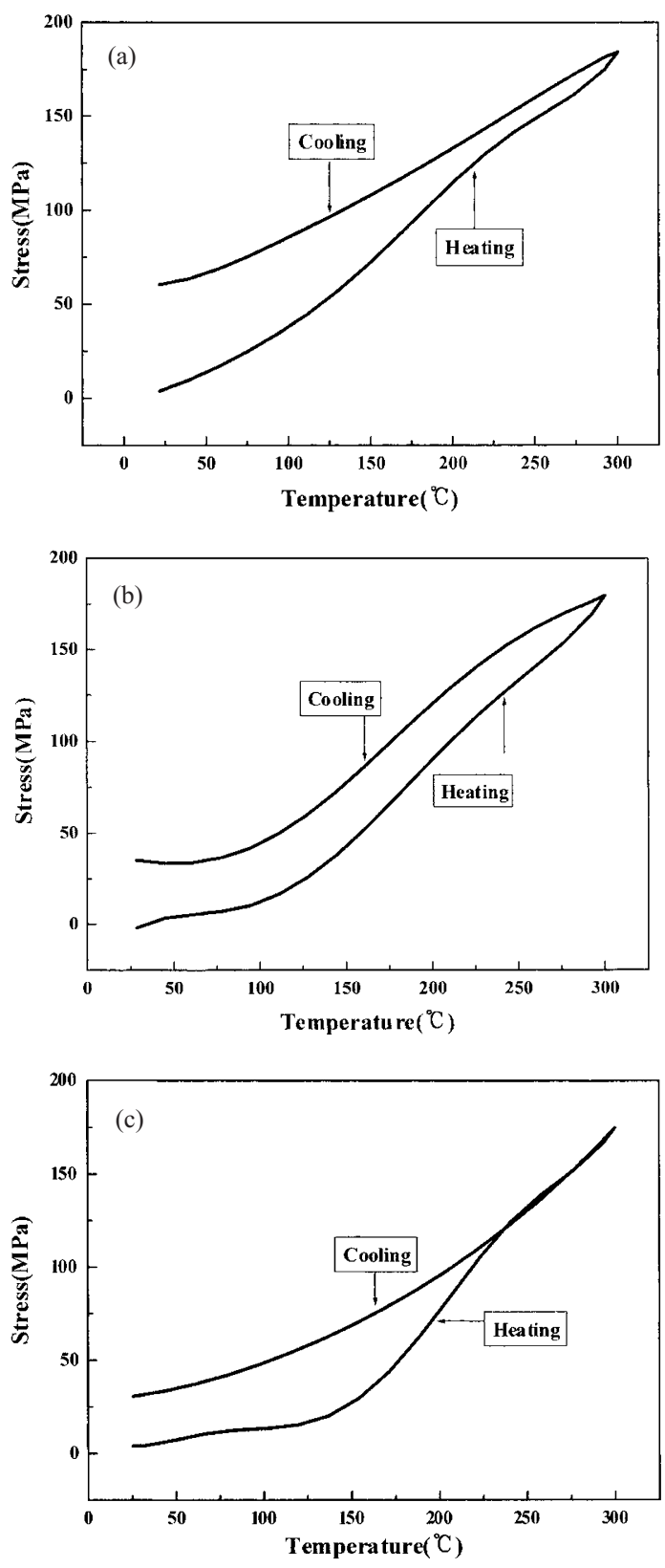

Figure 7. Stress behavior of PI films during drying (heating) and cooling processes at the scanning rate of (a) $2^{\circ} \mathrm{C} \mathrm{min}^{-1}$, (b) $4{ }^{\circ} \mathrm{C} \mathrm{min}^{-1}$, and (c) $6{ }^{\circ} \mathrm{C} \mathrm{min}^{-1}$, respectively.

the residual stress at room temperature. The stress increased when samples were heating up to $300^{\circ} \mathrm{C}$. When the heated samples were cooled down again, the stress was released to have the same stress as heating process. The stress development release was reversible when samples were heated or cooled.

Figure 9 shows the stress behavior of completely dried PI films during heating and cooling processes when films were heated above glass transition temperature. The stress decreased with heating above the glass transition temperature. Being different from the stress behavior in Figure 8, the stress was released at higher temperatures in cooling process. These results were caused by stress relaxation associated with increased 


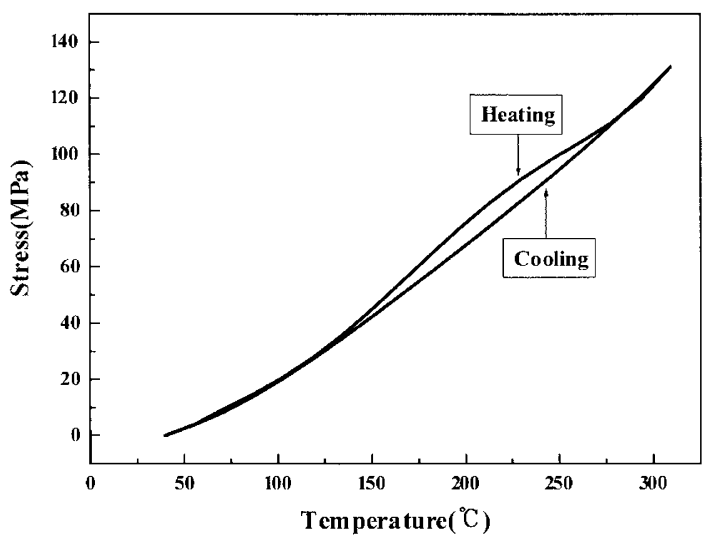

Figure 8. Stress behavior of completely dried PI film during heating and cooling process at the scanning rate of $4{ }^{\circ} \mathrm{C} \mathrm{min}^{-1}$.

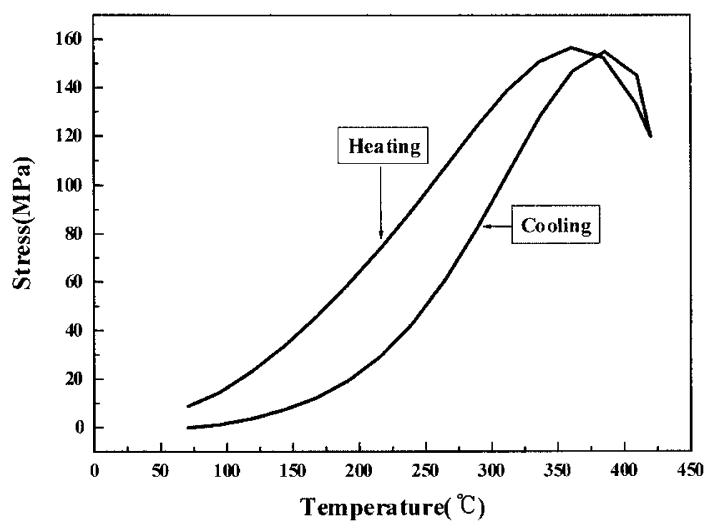

Figure 9. Stress behavior of completely dried film during heating and cooling processes. The temperature range was from 70 to $420^{\circ} \mathrm{C}$ at the scanning rate of $4{ }^{\circ} \mathrm{C} \mathrm{min}^{-1}$.

molecular mobility above the glass transition temperature. Residual stress could be eliminated by this operation schedule.

\section{CONCLUSION}

A new cage structured diamine, bis(4-aminophenyl)1-adamantyl phosphine oxide (DAAPO), was derived from 1-bromoadamantane. Aromatic polyimide containing admantane pentant group was synthesized from the reaction of DAAPO and 2,2bis(3,4-dicarboxyphenyl) hexafluoropropane dianhydride (6FDA). The dielectric constant of polyimide synthesized decreased from 3.03 to 2.49 with the film thickness from $1.14 \mu \mathrm{m}$ to $130 \mathrm{~nm}$. These dielectric values were lower than those of other aromatic polyimides reported. Stress was developed during baking PI films on the silicon wafer substrate. It increased with increasing temperature, and its behavior was affected by ramping rate. The residual stress was obtained when the dried film/substrate composite was cooled down to room temperature. Film thickness was in situ measured with bending curvature to determine accurate stress. Temperature scanning rate effect on the stress and film thickness behavior was similar in that the transition temperatures where their variation started and completed were similar each other. The strength of residual stress was possibly controlled by ramping and annealing processes.

\section{REFERENCES}

1. H. Satou and D. Makino, "Polyimides for Electric Application," Hitachi Chemical Co., Ltd., Ibaraki, 1993.

2. J. C. Coburn and M. T. Pottiger, in "Polyimides: Fundamentals and Application," M. K. Ghosh and K. L. Mittal, Eds., Marcel Dekker, Inc., New York, N.Y., 1996, pp 207-247.

3. K. Sato, K. Mukai, S. Harada, A. Saeki, T. Kimura, T. Okubo, I. Ishi, and I. Shimizu, "IEEE Trans on Hybrid and Packaging," 1973, Vol. PHP-9, p 173.

4. C. C. Chao and K. D. Scholz, "Proc. of 38th Electronic Component Conference," 1998, p 276.

5. R. A. Larsen, IBM J. Res. Dev., 26, 268 (1980).

6. L. J. Gibson and M. F. Ashyby, Proc. R. Soc., London, Ser. A, 382, 43 (1982).

7. J. H. Aubert and A. P. Sylwester, Chemtech, 21, 290 (1991).

8. J. L. Hedrick, Y. Charlier, R. Dipietro, S. Jayarman, and J. E. McGrath, J. Polym. Sci., Polym. Chem. Ed., 34, 2867 (1996).

9. Y. T. Chern, Tetrahedron Lett., 36, 5805 (1995).

10. Y. T. Chern, J. Polym. Sci., Polym. Chem. Ed., 34, 125 (1996).

11. Y. T. Chern and H. C. Shiue, Macromolecules, 30, 5766 (1997).

12. Y. Chern, Macromolecules, 31, 5837 (1998).

13. Y. Chern, Polymer, 39, 6643 (1998).

14. S.-H. Hsiao and C.-T. Li, Macromolecules, 31, 7213 (1998).

15. R. C. Fort, Jr. and P. V. R. Schleyer, Chem. Rev., 64, 227 (1964).

16. S. S. Novikov, A. P. Khardin, I. A. Novako, and S. S. Radchenko, Vysokomol. Soedin., Ser. B, 16, 155 (1974).

17. S. S. Novikov, A. P. Khardin, I. A. Novako, and S. S. Radchenko, Vysokomol. Soedin., Ser. B, 18, 462 (1976).

18. V. V. Korshak, S. S. Novikov, S. V. Vinogradov, A. P. Khardin, Y. S. Vygodskii, I. A. Novako, B. S. Orlinson, and S. S. Radchenko, Vysokomol. Soedin., Ser. B, 21, 248 (1979).

19. A. P. Khardin and S. S. Radchenko, Russ. Chem. Rev. (Engl. Transl.), 51, 272 (1982).

20. I. A. Novako and B. S. Orlinson, Vysokomol. Soedin., Ser. B, 37, 1209 (1995).

21. M. R. Pixton and D. R. Paul, Polymer, 36, 3165 (1995).

22. Y. T. Chern and W. H. Chung, J. Polym. Sci., Part A: Polym. Chem., 34, 117 (1996).

23. Y. T. Chern and H. C. Shiue, Macromolecules, 30, 4646 (1997).

24. S. K. Lim, D. K. Yoo, D. Kim, and T. H. Yoon, J. Polym. Sci., Part A: Polym. Chem., in press (2003).

25. M. I. Bessonov and N. P. Kuznetsov, in "Polyimides: Synthesis, Characterization, and Application,” K. L. Mittal, Ed., Plenum Publishing Corporation, New York, N.Y., 1984, pp 385-415.

26. T. Liang, Y. Makita, and S. Kimura, Polymer, 42, 4867 (2001).

27. L. Matay, "Proceedings of the 4 th International Conference on 
Advanced Semiconductor Devices and Microsystems," 2002, pp 83-86.

28. H. J. Kook and D. Kim, J. Mater. Sci., 35, 2949 (2000).

29. K. L. Saenger and H.-M. Tong, in "New Characterization Techniques for Thin Polymer Films," H.-M. Tong and
L. T. Nguyen, Eds., John Wiley \& Sons, Inc., New York, N.Y., 1990, p 95.

30. D. R. Lide, "Handbook of Chemistry and Physics," 76th ed, CRC Press, New York, N.Y., 1995. 